\title{
Playing the trump card of uncertainty
}

Republicans in the United States are promoting legislation that would insist on scientific risk analysis before any tightening of environmental regulation. The proposals are not acceptable.

PUBLICATION last month of studies showing falling sperm counts in British men is a reminder of the insidious threat posed by environmental pollutants. Not that pollutants are necessarily the source of the falling sperm counts reported over recent years. Changes in women's lifestyles may also have affected the development of male fetuses, while men's smoking and prolonged driving in tight trousers have also been suggested as possible causes. The statistics of sperm decline are themselves controversial. But endocrinedisrupting chemicals affecting fetal testes are prime suspects.

In assessing the potential impact of such pollutants, the current limitations of science are all too apparent. When, as with trace chemicals and particulates, low doses may be important, epidemiology becomes important. But it can accomplish only so much. True, it can provide useful information at lower levels of exposure than can be explored in laboratory tests on animals; it can also help to relate the results of such tests to effects on humans. But epidemiologists acknowledge that their studies of human populations can be unavoidably afflicted by statistical uncertainty, because samples sometimes have to be small. Such factors become important when apparently small consequences of low exposure may amplify the effects of common diseases. And although progress is being made in understanding mechanisms by which, for example, dioxins may harm humans, the number of possible molecular pathways in such cases is still considerable, while mechanisms are even less well understood for atmospheric particles that are suspected carcinogens.

Where the issues of pollution have become politicized, uncertainties within the science provide a notorious opportunity for the conflicting parties in any environmental dispute. That was the case when the chemical industry used its knowledge of atmospheric models to resist restrictions on chlorofluorocarbons, and when Greenpeace and UK Nirex, responsible in the United Kingdom for nuclear waste disposal, use hydrogeological models in disputes over Nirex's plans to test a site for a subterranean repository.

This week's Briefing (pages 10-14) focuses on the role of science within two debates which have become even more highly charged: the unprecedented involvement of right-wing politicians in environmental legislation in the United States, exemplified by debates over atmospheric particles; and the extraordinary (but possibly transitory) victory of Greenpeace over the Shell oil company in an environmentally innocuous plan (as it appeared to its originators) to sink an oil storage buoy - the Brent Spar - in deep water off northwest Scotland.

The common theme is science-based risk analysis. This can be seen pessimistically as a way of highlighting scientific uncertainties. After all, a classical risk analysis derives the probabilities of various outcomes by analysing all the possible paths by which each may materialize. So, for example, in assessing risks to human health from chemically contaminated fish, the US Environmental Protection Agency has presented a framework in which, for just one chemical, estimates of many factors ranging from possible environmental pathways to coefficients of absorption - all uncertain in conceptual terms or in measurement terms or both - have to be amalgamated to make a quantitative risk assessment possible. The accumulation of uncertainties looks daunting, and provides ample opportunity for groups with vested interests to promote a biased perspective. But such risk analysis, by assessing scenarios comprehensively, also has valuable potential for establishing common ground.

Suppose, in the case of Brent Spar, that the environmental impact analyses made by Shell are vindicated by the working group set up by the UK government. Greenpeace's accusations that Shell's science was deficient would be seen to be exaggerated, and the common ground between the factions might have increased. But Greenpeace is unlikely to change its position as a result because its overriding principle of environmental precaution in the face of residual scientific uncertainties and future dumping possibilities would still be politically tenable.

In the United States, Republican zealots and some industries are likely to go on playing the same card of uncertainty and precaution in the opposite direction for as long as they can, while as the Briefing describes - they propose risk-analysis legislation that would turn that card into a trump. But their position with respect to particulates is much less defensible than that of Greenpeace on Brent Spar, because the epidemiological evidence is so suggestive of significant risk to the population whereas mechanisms are poorly understood. The US legislature should reject the demands being made of science before regulatory change.

\section{Infected blood in Japan}

Japan's regulatory system for drugs and other medical treatment needs to be completely overhauled.

THE scandal about the infection of thousands of Japanese haemophiliacs with HIV in the mid-1980s through the use of contaminated blood coagulants is coming to a head. After some unusually frank disclosures by the new head of the ministry of health, Naoto Kan, about the government's failure to take prompt action to prevent the spread of HIV through imported blood products that had not been heat-treated to kill viruses (see Nature $379,663 \& 760 ; 1996)$, attention is now focused on the individuals responsible. For the sake of the haemophiliacs infected and their relatives, it is essential that justice should be done and that all of those immediately responsible should be brought to task. But in this witch-hunt, Japan must not lose sight of the wider issue of the fundamental defects in Japan's system for drug approval that allowed the flawed decisions of these individuals to pass.

Japan has the highest per capita drug consumption in the world. Yet drug approval is regulated by only a handful of ministry officials, most of whom have no scientific qualifications. Beyond the ministry walls there also is a severe shortage of qualified experts to advise on newly emerging diseases such as AIDS, and, in Japan's hierarchical society, one or two senior academics can wield enormous power in the decision-making process.

There is no quick solution. Japan needs to upgrade its medical research organizations and produce more high-quality medical researchers. There is a crying need for an organization staffed by competent scientists to regulate drugs and new methods of medical treatment. Furthermore, Japan needs to ask why, despite having one of the highest rates of blood donation in the world, the country is still so dependent on imported blood products. 